\title{
Single Sided Deafness: A Treatment Option
}

\author{
Bahgat El Sherif* \\ Clinical Audiology \& Hearing Therapy, University Isabel I, Spain
}

*Corresponding author: Bahgat El Sherif, Clinical Audiology \& Hearing Therapy, University Isabel I, Spain

\begin{abstract}
Single sided deafness (SSD) is established when the patient has normal hearing in one ear and severe to profound hearing loss in the other one, and measured by pure tone audiometry as hearing threshold (over $0.5,1,2$, and $4 \mathrm{KHz}$ ) of at least $70 \mathrm{~dB}$ hearing level in the affected ear and not more than $30 \mathrm{~dB}$ HL in the better ear. The causes of single sided deafness include many pathologies such as: temporal bone trauma, Meniere`s disease, vestibular schwannoma, cochleovestibular abnormalities, vascular ischemia, autoimmune disease, and infection. Idiopathic cause is commonly encountered. The advantages of binaural hearing include head shadow effect, binaural summation, and binaural squelch. The diminished ability to orient and understanding meaning of patient with SSD have negative impact on quality of life which may be equal the effect of bilateral loss, also, it may threaten safety. The conventional treatment of single sided deafness was contralateral routing of sound and Osseo integrated implants. Both forms of the treatment are effective in addressing head shadow effect but have no advantage to provide psychoacoustic information to deaf side i.e. squelch and summation effects, which are mandatory to improve speech perception in noise. The cochlear implant is the only treatment modality that offers bilateral listening that improve recognition in noise and sound localization. Results from studies and satisfaction questionnaire confirmed the superiority of CI and significant performance improvement regarding sound localization, speech perception and marked tinnitus improvement.
\end{abstract}

\section{Introduction}

As esteemed Professor Dr. Jan Helms puts it "from my perspective, cochlear implants are the most significant medical development in the second half of the twentieth century, as they replace an entire sensory organ". Single sided deafness (SSD) is a condition where the patient has normal hearing in one ear and severe to profound hearing loss in the other ear. In the adult general population, it affects between $12-27$ per 100,000 adults. In most of cases the hearing loss is due to sudden or idiopathic causes [1]. The incidence in pediatric and adolescent population is 0.4 to 3.4 per 1,000 live births and continues to increase through the childhood, with a prevalence in school- aged children of 3 to $6 \%$ [2-4]. SSD patients have been underestimated historically, and previously either have been observed without intervention, or have been treated with contralateral routing of signal (CROS) hearing aids or bone conduction devices (BCDs) [5,6]. The diagnosis of congenital hearing impairment from early days of life is available due to the programs of hearing screening of newborn. When the profound hearing loss is diagnosed and treated early in life, speech and language can be developed by exposure to sound. The adaptation of the brain to experience by the time, but its utmost plasticity is during the first few years [7]. As shown by studies, spoken language is better in bilaterally cochlear implanted children who have bilateral loss than others who have unilateral cochlear implant, and as early possible and younger as the implantation is, the better the performance. SSD especially in children result in slower language acquisition, poor academic performance, increased listening effort, and poor quality of life compared to normal hearing subjects $[8,9]$. Cortical auditory evoked potentials in children with SSD are obviously different than those obtained in normal hearing controls [10].

The causes of single sided deafness include many pathologies such as: temporal bone trauma, Meniere`s disease, vestibular schwannoma, cochleovestibular abnormalities, vascular ischemia, autoimmune disease, and infection. Idiopathic cause is commonly encountered. Sudden onset of SSD is often reported, and results in significantly suffering patients $[11$,$] . Despite normal contralateral$ 
hearing, deficits and disability were reported as time elapsed. More effort is needed to compensate for the deficit, results in auditory fatigue [12-15] and reduced performance. This handicap is strongly related to deficits in spatial perception.

\section{Advantages of binaural hearing}

The advantages of binaural hearing include the head shadow effect, binaural summation, and binaural squelch [16]. The head provides a physical barrier to sounds, causing an attenuation of the signal in the ear not directed at the source. The head shadow effect varies according to the frequency and position of the signal. The head shadow effect occurs when speech and noise are spatially separated, in which the head originates an acoustic shadow resulting in an improved signal to noise ratio (SNR) in one ear enables the listener to selectively present to the ear with the better SNR. The head shadow attenuates high frequency sounds by about $20 \mathrm{~dB}$ and low frequency sounds by only 3 to $6 \mathrm{~dB}$ [17], and it does not require higher level cortical processing and binaural squelch occurs when speech and noise are spatially separated, and different inputs are delivered to both ears. To achieve binaural squelch advantage, the central auditory processing is required to integrate the signal from each ear alone at the level of the auditory cortex to improve audibility. In noisy environments, a 2-6 dB in signal threshold is added by the higher order auditory processing. At the same time, the squelch effect reduces SNR by 2 to $3 \mathrm{~dB}$ which improve the ability to differentiate sound of interest from background noise [18]. The limited evidence is supporting the objective benefits of binaural squelch [19]. Binaural summation which is central auditory processing effect takes place when both ears received similar signal and relies on varying SNR between ears. Also, the central processing of the combined signal lead to improvement in speech perception in quiet environment and is useful in background noise due to increase of perceptual loudness by up to $3 \mathrm{~dB}[20]$.

Sound localization depends on two factors, the first one is interaural timing difference (ITD) which is the difference in arrival time for the stimulus between the two ears, and the second one is the interaural level intensity difference (ILD) which is the difference in the intensity of a stimulus reaching both ears. ITD is $0 \mu \mathrm{s}$ as the sound delivered directly to the front of the person and is increasing up to the maximum value of $\sim 600 \mu \mathrm{s}$ when the signal presented \pm 90 • azimuth because ITD value increases when the sound goes laterally in horizontal plane. So, the sound will be detected by the ear nearest to the sound of the interest before the other ear which is more far from the delivered sound. ILD gives the benefit that the more intense signal is perceived by the ear closer to the stimulus compared to other one [21] and it increases when the signal deviates away from 0 - azimuth. Both ITDs, and ILDs are a frequency-dependent and $20 \mathrm{~dB}$ of attenuation or more could be achieved in the level difference as a function of frequency because of head shadow effect. The binaural auditory system depends on phase delays caused by ITDs when low frequency sounds (below $800 \mathrm{~Hz}$ ) is presented, and for high frequencies (i.e. higher than $1600 \mathrm{~Hz}$ ) the first signal for localization comes from ILDs which arise mainly from the head shadow effect [19,22]. In the midfrequencies between 800 and 1,600 $\mathrm{Hz}$ ) both ILD and ITD are used. For spatial hearing, the integration of acoustic information from both ears is needed, and gives precise information for speech processing, localization, the segregation of auditory streams and the perception of fused sounds. The binaural hearing signals has a great benefit in spatial hearing abilities, and the monoaural signals provide the information concerning about the ability to determine the distance of a sound source the ability to determine the distance of a sound source.

\section{Effect of SSD}

The diminished ability to orient and understanding meaning in patients with SSD have negative impact on quality of life which may be equal the effect of bilateral loss $[11,23]$. To overcome the effect of SSD, an extra 3-10 dB is needed to be added to achieve the same perceptual improvement of binaural summation of the signals [24-26]. So, patient with SSD exert a more effort and attention to attend to a target speaker. This effect may manifest as distracted, inattentive, or even unaware of a talker positioned at the affected ear specially in difficult situation where the signal to noise ratio is poor. Therefore, a need to modify to maximally position the good ear for hearing.

\section{Consequences of single sided deafness in children}

\section{Spatial hearing and binaural processing}

Single sided deafness has negative impact not only on quality of life, but it may threaten safety. SSD patients encounter troubles in spatial and hearing binaurally which result in localization error up 280 compared to 40 and 60 in normal hearing [27,28]. To get performance like normal hearing persons to determine sentences and nonsense syllables, improving listening condition by increasing SNR between 2.5- and 8-dB is needed [29,30]. Lieu et al. [31] in a study of 107 children with SSD using CID W-22-word list reported poorer word recognition scores in quiet and in babble noise. Other study by Reeder et al. [28] of twenty patient aged 6-17 years- old children with SSD compared to normal hearing controls reported badly affected word recognition ability even when the words were presented in quiet. When the noise was delivered from the front of the person, the performance was equal in normal hearing $(\mathrm{NH})$ and children with hearing impairment (HI). But NH children have the advantage of spatial unmasking if the direction of the sound changed to right or left. In moderately severe to profound SSD affected children better word identification in noise was achieved 
only when the noise was moved to the deaf ear. Annoying results of badly affected sound localization ability in SSD affected children, as they are subjected to hours of environmental noise each day [32]. The learning ability is affected because of diminished ability to listen in noise, also because children require a more SNR than adults to achieve equal speech recognition scores. To help children with SSD to get suitable conditions for learning, improving the SNR should be considered in addition to improving environments of the classroom and addressing auditory distraction. Kral et al. [33] in his study concluded that abnormal changes in individual wiring and coupling patterns in the brain which cause sensory loss and negatively affect the development of spoken language and higherorder cognitive skills in congenitally deaf children.

\section{Processing of the neurons}

Early childhood is a critical and sensitive time for brain development, and loss of auditory input either acquired or congenital during the developing time has serious bad impact on growth of the cortex, and synaptic development [7,34,35] which leads to changes in auditory and other brain parts [34,36-40] and as the brain works as a whole and not in isolation parts as stated by Kral et al. [33] who presented the connectome model, the changes in the auditory and other brain parts could be manifested as affected functional connectivity of the brain responsible for executive functioning, cognition, and language comprehension [41].

\section{The development of neurocognitive factors}

\section{Spoken language: infancy}

The early detection of hearing loss provided by neonatal hearing screening is very useful in early management and to avoid bad impact of undetected or late diagnosis of hearing loss which may be diagnosed or noticed when the child starts walking. Unfortunately, diagnosis of SSD during the first year of life could be easily missed, because of quiet surrounding [32], sleeping a lot of time, and the delivered sound and perception are at short distance from one-to-one. The negative effects of SSD include a delay of 5 months in infant with SSD to produce two-word phrases compared to $\mathrm{NH}$ children as concluded by Kiese-Himmel [42] and delays of the language in preschool period was reported by Borg et al., 2002. The natural listening condition of the proper acoustic information that enables incidental learning is badly affected because of reduced auditory stimulation and loss of binaural summation, that in turn, lead to poor acquisition of terminology, language rule formation, and comprehensive orientation about the surrounding [43].

\section{Memory, schooling, and executive performance}

Altered language development is not the only negative impact in brain due to reduced auditory input, but the general neurocognitive functioning is also affected $[33,44]$ as Lower (verbal) IQ scores
[45-47], and affected complicated verbal working memory task [46]. Keeping verbal information while processing unrelated verbal information is difficult in SSD patients. Attitude and academic performance are negatively impacted due to bad phonological processing regarding accuracy and efficacy which is clearly noticed with unusual verbal information $[48,49]$. Beside the struggles at school that lead to repeating a grade that reach up 35\% of SSD, the social and emotional problems are also considered $[48,50]$. So, proper handling of management and providing perfect listening condition as in classroom should be considered.

\section{Objectives}

The objective of this thesis is to evaluate cochlear implantation as an effective modality in treatment of single sided deafness in both children and adults, and its impact on sound localization, speech perception, and tinnitus.

\section{Method}

A search in PubMed was done to collect studies of single sided deafness, unilateral cochlear implant, and tinnitus during the last two years. A case study, paper in languages other than English and animal studies were excluded. The search using SSD and unilateral CI results in 23 papers. The search using SSD and tinnitus results in 10 papers. Three repeated papers and one paper for case study were excluded. So, the net result was 29 papers. Using Boolean operators, the keywords used were Single Sided Deafness and unilateral cochlear implant and single sided deafness and tinnitus.

\section{Results}

\section{Cochlear implant as treatment for SSD}

In the past, SSD were not considered as a big issue to deal with, as there was a wrong belief that the good ear would compensate and overcome the deficit, so, there was no motivation or interest to manage it by any available treatment option as providing contralateral routing of signal (CROS) hearing aids, bone conduction devices (BCD), or preferential classroom seating for children. The CROS aid system works by routing the signals by a microphone worn on the affected ear to a receiver on the better ear, so, it bypasses the loss of head shadow. The CROS aid system does not provide the user with true binaural hearing, at the same time it is not tolerated well by the user and show impaired user satisfaction [5,6]. BCDs work by stimulating a single auditory pathway of the better ear by vibrating the skull. They give the advantage of improvement in speech perception in noise, but they did offer proper sound localization [51,52]. The binaural stimulation of the auditory system can be achieved by different ways as (bilateral cochlear implant [CI], binaural amplification, normal acoustic hearing, and binaural bimodal amplification). The binaural stimulation has several advantages as improvements in detecting sound localization, better 
understanding and identification of speech in noise, enhance music estimation, better pitch and melody recognition, and improvements in quality of life [53-59]. In addition, the benefit of binaural bimodal stimulation was the same benefit of binaural listening achieved in those patients with bilateral acoustic hearing or bilateral electric hearing $[60,61]$. Unfortunately, severe deterioration of the central auditory processing strategies and impair auditory function and quality of life could be resulted from unilateral loss, so, all comprehensive clinic evidence and studies highly recommend the effectiveness and importance to restore binaural stimulation and hearing.

It was thought that the auditory central processing cannot compensate between the acoustic and auditory signals until 2008 when van de Heyning et al introduce CI as a treatment for controlling the tinnitus. The results demonstrated decreased tinnitus effect [62]. The effects of CI on binaural hearing were studied by Vermeire and Van de Heyning in 2009 which demonstrated marked improvement for head shadow effect, moreover the binaural squelch and summation effects were improved by the same degree. Subjective marked improvement by assessing speech, spatial, and quality of hearing scale (SSQ) was obtained with CI over SSD condition [63]. Objective results comparing CROS aids, BCDs, and CI demonstrated the superiority of the results of CI regarding better speech perception in noise in all cases when compared with unaided when the SNR favored the affected ear as in patients who received $\mathrm{CI}$, they respond much better on speech perception testing than in CROS or BCD cases when the affected ear received the poorer SNR [18]. SSD patients who received CI, either children or adults, demonstrated better speech understanding in the aided ear but scores over the unaided SSD were markedly improved even in competing listening situations, as roving speech in noise and multidirectional noise $[64,65]$. Studies also stated that the performance of the normal hearing ear was not affected at all by $\mathrm{CI}$ in the affected ear, eliminating the theory of conflicting normal acoustic ear and fully electrically stimulated one $[18,66,-68]$.

\section{The effect of cochlear implants on sound localization}

Assessing sound localization provided by $\mathrm{CI}$ as treatment modality for SSD was studied by Arndt et al. who compared the accuracy in patients between CROS, BCD, unaided conditions, and cochlear implants six months after implantation in a cohort of 11 patients. The study was done by placing seven loudspeakers at intervals of 30 degrees from -90 degrees to 90 degrees in a frontal semicircle $2 \mathrm{~m}$ in diameter in a horizontal plane at the patient's head level in a front of the patients, and asked them to determine which speaker delivered the sound. Patient with cochlear implant demonstrated marked less localization error compared to those in unaided condition ( $p=0.003)$, and those with osseointergrated implant ( $\mathrm{p}=0.002)$, and patients with CROS devices ( $\mathrm{p}=0.001)$ [18]. Another study by Zeitler et al. who assessed sound localization by comparing SSD patients who received CI, normal hearing subjects, bilateral CI patients, and unaided SSD, demonstrated that all patients with CI showed marked improvement, and they were able to localize sound perfectly as patients with bilateral CI. A small proportion of patients can localize in the 95th percentile of normal hearing [64]. Firszt et al. [67]; assessed localization by using monosyllabic words delivered randomly from a 15-loudspeaker arranged in an arc, 10 degrees apart, with 10 active and 5 inactive speakers at a roved $60 \mathrm{~dB}$ SPL $( \pm 3 \mathrm{~dB})$ level. The patient was positioned $3 \mathrm{ft}$ in front of the central loudspeaker and ten words were presented from each of the active loudspeakers. the patient was asked to only identify the speaker location for each presentation. The results were stated that seven adult's patient receiving cochlear implantation out of ten showed improvement in sound localization in bimodal condition compared with hearing aid only. Cardieux et al. [28]; investigated five patients with SSD who received a cochlear implant and showed a marked improvement in bimodal scores in three patients compared with those in HA-only.

\section{The effect of cochlear implants on speech perception improvement}

Arndt et al. [18] studied speech perception using three conditions and compared CROS and bone-anchored hearing aid (BAHA) device recipients. The test was done in a sound treated room via 2 of 3 loudspeakers, at angle of $+450,00$, and -4501 $\mathrm{m}$ away from the patient's head. The sound delivering setups S00N00, S+450N-450, and S-450N+450 were used in background noise. Speech comprehension in noise was evaluated by using the Hochmair-Schulz-Moser (HSM) sentence test [69] and the Oldenburg sentence test (OLSA) [70,71]. Regarding the patient's deaf ear, the patterns to deliver sound and speech were S0N0 (speech and noise from the front), Snh Nssd (speech from the normal hearing side/noise from the unilateral deaf side), and Sssd Nnh (speech from unilateral deaf side/noise from normal hearing side). Speech and background noise were delivered at 65 $\mathrm{dB}$ SPL with signal-to-noise ratio (SNR) of $0 \mathrm{~dB}$ using the HSM test. The percentage of correct words detected was calculated as an estimation of speech comprehension. The results confirmed that significant improvement in speech perception in patient received $\mathrm{CI}$ in the Snh/Nssd and Sssd/Nnh configurations compared to those with CROS (p 1/4 0.031 and p 1/4 0.03) or osseointegrated implant devices ( $p 1 / 40.023$ and $p 1 / 40.001$ ). The only configuration where CI was significantly superior to an unaided condition was Sssd /Nnh (p 1/4 0.001). There was no significant difference in improvement between the groups when the noise was directed head-on.

Firszt et al. [67] studied 10 patients with asymmetric hearing loss (7 post lingually and 3 prelingually), used materials and conditions that simulates real-life listening situations, avoid ceiling and floor effects. Both quiet and background noise conditions 
were used to measure the word and sentence, by either fixed or adaptive noise. Consonant-vowel nucleus-consonant (CNC) monosyllabic words [72] were delivered at $60 \mathrm{~dB}$ SPL. Hearing in noise test (HINT) sentences and TIMIT sentences $[10,67,73,74]$ were delivered at $60 \mathrm{~dB}$ SPL at a $+8 \mathrm{~dB}$ signal to noise ratio (SNR) using four-talker babble. The sentences and noise were delivered from the same loudspeaker away $3 \mathrm{ft}$ in front of the listener. The TIMIT sentences were also delivered in quiet at $50 \mathrm{~dB}$ SPL. The HINT sentences are four to six words in length, and have been used with CI user, by a male talker. The TIMIT sentences range from four to eight words, male and female talkers are included, a variety of regional dialects, and multiple speaking rates. The TIMIT sentences are more difficult comparing with the HINT sentences, as well as more representative of real-life listening situations because of the variety of speakers and lack of predictability. Firszt et al. [67] showed a marked improvement in speech perception in the only CIonly condition at the six-months interval as follow: Hearing in Noise Test (HINT), $\mathrm{p} \leq 0.001$; TIMIT in noise, $\mathrm{p} \leq 0.01$ : TIMIT in quiet, $\mathrm{p} \leq$ 0.001 , and Constant-Vowel Nucleus-constant (CNC), $p \leq 0.001$. The bimodal condition demonstrated a marked improved performance only in TIMIT sentences in quiet places ( $p \leq 0.05$ ). One of the three pre-lingual patients had open-set speech recognition with the CI.

Távora-Vieira et al. [75] investigated twenty-eight patients (15 women and 13 men) with unilateral sensorineural severe-toprofound hearing loss were included in this study.

Thirteen of them had tinnitus. The adaptive Bamford-KowalBench speech-in-noise (BKB-SIN) test [76], which evaluates the signal-to-noise ratio required to get a score of $50 \%$ of the words correct was used to evaluate speech perception. Tests were done in a free field, with the patient seated $1 \mathrm{~m}$ away from loudspeakers located at angles of $0,-90$, and +90 degrees. The spatial configurations used for speech testing were S0/N0, speech and noise delivered from the front; S0/NHE, speech delivered from the front and noise to the normal-hearing ear; and SCI/NHE, speech delivered to the implanted ear and noise to the side of the normal-hearing ear. The spatial configuration SCI/NHE was chosen for the most challenging situation as clinically determined by the patient. The results confirmed marked improvement in speech perception in noise scores when speech and noise delivered from the front and in the following order: S0/NHE ( $p=0.003$ ) and Sci/ NHE $(p<0.001)$. The speech perception improved in the SCI/NHE agreed with the results founded by Arndt et al. [11]. There was no correlation between age at implantation and the duration of the deafness [75].

\section{The effect of cochlear implant on tinnitus}

A perception of sound with no external sound source is defined as a tinnitus. The pathophysiology of tinnitus is not yet clearly understood [41]. Several theories suppose central nervous system origin resulted from suboptimal or maladaptive plasticity , leading to reorganization and hyperactivity in central auditory and nonauditory structures as result of a peripheral lesion of the cochlear hair cells [41,77-81] so, cochlear implantation as an option to regain hearing could affect tinnitus perception. The advantage cochlear implant not limited only to restore hearing, but it also provides a treatment option for tinnitus as confirmed from data of a systematic review which confirmed its positive impact on tinnitus perception when applied to treat patients with bilateral hearing loss regarding the Tinnitus Handicap Inventory (THI), tinnitus loudness, and annoyance [82]. Van de Heyning et al. [62] were the first to do a trial of fitting $\mathrm{CI}$ as a treatment of tinnitus in patients with SSD of post lingual onset. This and the following studies confirmed the positive impact and efficacy of $\mathrm{CI}$ in treating tinnitus in SSD $[62,83]$. The results obtained confirmed improvement of speech in noise and sound localization after CI [84].

The most widely used questionnaires among different questionnaires used to evaluate the tinnitus either exclusively or in combination were the THI [85] and the visual analog scale (VAS) [86]. The Tinnitus Handicap Inventory (THI) was graded according to the following scores: slight (0-16), mild (18-36), moderate (38$56)$, severe (58-76), and catastrophic (78-100). The subjective tinnitus perception levels are measured by The VAS by instructing the patients to make a sign on a line of about $10 \mathrm{~cm}$. the left end indicate "quiet" and the right end indicate "very loud". The distance from the left end to the marked point indicate the subjective level of the tinnitus $[87,88]$. A numeric scale from 0 to 10 in some studies but evaluated as VAS. Many characters of tinnitus including loudness, awareness, annoyance, degree of disability, stress, mood, and ability to influence the tinnitus can be also evaluated by VAS $[18,83,89-92]$.

\section{Effect of tinnitus on auditory perception}

Most of patients with single sided deafness (54\%-84\%) suffering from severe tinnitus, which can badly affect their life quality $[93,94]$. The ability of CI as a treatment option of SSD patient with tinnitus and reduction of tinnitus severity was confirmed by Van de Heyning et al. [62]. In a study by Liu et al. [95] 14 out of 26 SSD patients (54\%) had tinnitus, and when noise was delivered to the front or to the deaf ear of SSD associated with tinnitus, the performance was poorer than others with SSD without tinnitus. The same results were obtained by Mertens et al. [96]. A $2.4 \mathrm{~dB}$ was recorded when noise directed to the affected ear as biggest difference, and a $0.7 \mathrm{~dB}$ was recorded when the noise directed to $\mathrm{NH}$ ear as the smallest result. The spatial condition has a role in poor performance resulted from tinnitus. The relationship between the impact of severity of the tinnitus and speech recognition at spatial conditions (SON0, S0ndeaf) was confirmed. Poor sound localization was affected by severity of the tinnitus measured by 
either THI ( $\left.\mathrm{p}^{1 / 4} .005\right)$ or VAS ( $\mathrm{p}^{1 / 4}$.003) [95]. There is a difference in performance between SSD patients with tinnitus (RMSE 50.5) which was poorer than SSD patients with no tinnitus (RMSE 38.8). Decreasing tinnitus severity as an outcome of CI was confirmed by most of the studies [27,62], Liu et al. [95] suggested that CI has positive impact on sound localization and decreasing tinnitus which helps in improving speech recognition.

In a study by Van de Heyning et al. [62] who was the first used cochlear implant as treatment of tinnitus- including twenty two patient in the cohort had tinnitus demonstrated that suppression of the tinnitus was obtained in three patients, improvement in 18 and one with no response. Távora-Viera et al. [75] showed a marked reduction of the disturbance resulted from the tinnitus ( $p$ $=0.011$ ), using Tinnitus Reaction Questionnaire (TRQ). Ramos et at., (2012) who studied ten patients showed suppression of tinnitus in two patients, decreased tinnitus severity in seven patients, and no change in one patient after cochlear implant. A fall from $72.1 \%$ preoperatively to $14.3 \%$ in the tinnitus retaining therapy (TRT) at three months post implantation. The VAS reported a reduction from 7.9 points before surgery to 2.7 points at 3 months post implant.
Punte et al. [97] reported relief of tinnitus in patients with single sided deafness post cochlear implant. A drop in the average VAS to 4.36 (SD =1.31) (p = 0.027) to $4.36(\mathrm{SD}=1.31)(\mathrm{p}=0.027)$ at three months later from $\mathrm{CI}$ activation, and to 3.5 points $(\mathrm{p}=0.042)$ at six months later. A drop (from 60.0 to 39.4) ( $p=0.041$ ) of the total score by tinnitus questionnaire evaluation (TQ). Mertens et al., (2013) compared the impact of CI on loudness of the tinnitus when the device is on and off condition, and showed significant decrease of tinnitus loudness as the score of VAS dropped to 3.4 ( $\mathrm{SD}=2.5$ ) when the device was on, from 7.2 (SD = 2.6) when it was off ( $p<$ 0.01 ), in addition to improvement in speech reception threshold (SRT) in on condition ( $\mathrm{p}<0.01)$. Arndt et al., (2011) showed that median intensity severity reduced markedly in the VAS score (from 10 to 5$)$ when the cochlear implant was on $(p=0.0078)$ after six months of the implant. Five patient reported absolute suppression of the tinnitus with activated speech processor. In a systemic review by Nicole et al., (2019), table 1, reported that cochlear implantation is a good modality of treatment of tinnitus in SSD patients, as the obtained results of about $90 \%$ of counseled patients with SSD and severe tinnitus confirmed improvement of tinnitus after CI.

Table 1: Complete Overview of the Study Characteristics.

\begin{tabular}{|c|c|c|c|c|c|c|c|c|c|}
\hline Study & Sample size & $\begin{array}{l}\text { No. with } \\
\text { Preoperative } \\
\text { Tinnitus }\end{array}$ & $\begin{array}{c}\text { Follow-up, } \\
\text { mo }\end{array}$ & $\begin{array}{l}\text { No. of } \\
\text { Patients in } \\
\text { Follow-up }\end{array}$ & Male & Female & $\begin{array}{l}\text { Age, Mean } \\
\text { (SD), y }\end{array}$ & $\begin{array}{l}\text { Implant } \\
\text { Type }\end{array}$ & Questionnaire(s) \\
\hline $\begin{array}{l}\text { Távora- } \\
\text { Vieira et al. }\end{array}$ & 28 & 13 & 24 & 28 & 15 & 13 & $53.8(11.6)$ & MED-EL & TRQ \\
\hline Seo et al. & 16 & 16 & 6 & 16 & 10 & 6 & $51.9(13.7)$ & MED-EL & THI/VAS \\
\hline Ramos et al. & 10 & 10 & 3 & 10 & 4 & 6 & 42.7 (NE) & Cochlear & THI (Spanish)/VAS \\
\hline Punte et al. & 26 & 26 & 24 & 26 & NE & $\mathrm{NE}$ & $\mathrm{NE}$ & MED-EL & VAS/TQ \\
\hline Holder et al. & 12 & 12 & 12 & 8 & 10 & 2 & $51.6(15.5)$ & $\begin{array}{l}\text { Cochlear/ } \\
\text { MED-EL }\end{array}$ & THI \\
\hline $\begin{array}{l}\text { Buechner } \\
\text { et al. }\end{array}$ & 5 & 5 & 10 & 5 & NE & $\mathrm{NE}$ & $50.0(5.2)$ & $\begin{array}{l}\text { Advanced } \\
\text { Bionics }\end{array}$ & VAS \\
\hline Arndt et al. & 11 & 10 & 6 & 11 & $\mathrm{NE}$ & $\mathrm{NE}$ & $43.5(11.9)$ & Cochlear & VAS \\
\hline Dillon et al. & 20 & 20 & 12 & 20 & NE & $\mathrm{NE}$ & $50.0(11.5)$ & MED-EL & THI \\
\hline $\begin{array}{l}\text { Härkönen } \\
\text { et al. }\end{array}$ & 7 & 6 & 28 & 6 & 2 & 5 & $48.0(\mathrm{NE})$ & Cochlear & VAS \\
\hline Kitoh et al. & 5 & 5 & 12 & 5 & 1 & 4 & $52.2(18.5)$ & MED-EL & THI \\
\hline
\end{tabular}

\section{Discussion}

The conventional treatment of single sided deafness was routing of sound to other normal hearing ear and osseointegrated implants. Both of them offer advantages regarding head shadow effect but have no advantage to squelch and summation effects (i.e. psychoacoustic information to deaf side) which are mandatory to improve speech perception in noise. The cochlear implant is the only treatment modality that offers bilateral listening that improve recognition in noise and sound localization. Several studies (Arndt et al., 2011; Firszt et al., 2012) confirmed statistically the positive impact on sound localization in bimodal condition than unaided or CROS/osseointergrated conditions. Other studies [11,28,63,67] confirmed speech perception improvement. Two of them $[18,75]$ confirmed that the speech understanding was markedly improved in most difficult situations when sound is delivered at cochlear implant side and noise at normal hearing ear. Studies by Vlastarakos et al. [98] and Van Zon et al. [99] confirmed better speech perception in SSD patients receiving CI. One study by Távora Vieira et al. [75] reported statistically better performance with a configuration with sound and noise introduced to the patient's front (S0/N0). High satisfaction was reported between adults who received CI. In 19 patients who choose CI for treatment of their post lingual onset of 
SSD Finke et al. [100] studied the reason for that choice and stated four reasons:

a) Poor sound localization, that affect their safety in traffic.

b) To get rid of and end their suffering from tinnitus and noise sensitivity.

c) To look for better life quality, and

d) Reduce their anxiety to lose hearing in the second ear.

All patients confirmed that choosing $\mathrm{CI}$ as a treatment option was correct and satisfactory. The benefit of CI after one year of insertion was investigated in ten patients who developed SSD post lingually by Louza et al. [101] who confirmed marked improvements of speech intelligibility, spatial hearing, and basic sound perception. Hansen et al. [102] studied the benefit of CI in patients who developed SSD post lingually an improvement in word scores by $28 \%$, and in sentences scores by $40 \%$ when he did comparison between pre-implantation unilateral free-field audio stimulation to electrical CI stimulation 6 months post-implantation, with most of patients stated that they have significant improvement regarding speech perception in the CI ear. In 2008, Van de Heyning confirmed the effectiveness of $\mathrm{CI}$ as a treatment of tinnitus in patient with SSD when the other modalities as retraining therapy, sound therapy or drugs failed to control the tinnitus [11,62,75,96,97]. The efficacy of CI to control tinnitus can be explained as result of habituation, acoustic masking, direct stimulation of the cochlear nerve and organization of cortical pathways [103]. Five studies confirmed statistically marked reductions of the symptom as a relief or suppression [18,62,75,96,97]. Hassepass et al. [104] studied acquired SSD treated with CI. Post lingually deafened two children (10 and 11 yrs.) were studied and showed better speech recognition in noise if the speech presented to the $\mathrm{CI}$ ear and noise to the NH ear and better sound localization at 6- and 12-months post-implantation. Results from the speech, spatial and qualities of hearing scale confirmed better hearing ability in daily listening situations in a period of 12 months post implantation.

Arndt et al. [104] later studied the effect of CI in children with SSD of various onset. Speech recognition, localization and subjective benefit at 12 months post implantation were recorded in nine patients who had post lingually SSD, and the devices were used all time. Two contrasting results were reported from two children who had prelingually SSD: one reported well performance, and the other showed minimal benefit. Markedly poorer results were reported in two children in sentence orientation and understanding in noisy places when the signal was delivered to the good ear and noise to the CI ear, in comparison to preimplantation. But, if the signal and noise were delivered from the front, and when the signal was delivered to the $\mathrm{CI}$ ear and noise to good ear the performance was the same [105-110]. One child stopped using the device and showed non improving sound localization. Data of Tavora-Vieira and Rajan showed Binaural integration was confirmed clinically as willing and ability to wear the $\mathrm{CI}$ all the time and responses to sounds was obtained in one child with SSD of congenital onset who received CI at 21 months old [111-115]. Tavora-Vieira and Rajan showed data after 36-month follow up; the child had an optimum score on a free field speech perception test with masking the normal hearing ear with speech noise and could lateralize sounds when presented at -900 and 900 perfectly [116-118].

\section{Conclusion}

Single sided deafness has its negative impact on spatial hearing characterized by impaired sound localization and speech perception in addition to tinnitus. Conventional treatment by rerouting signals to normal hearing side does not offer binaural hearing, and only reduces the negative effect of head shadow and improves hearing in noise when the signal of interest is delivered at the deaf ear. The cochlear implant is the only modality of treatment that offers the potential to restore binaural hearing in adult and children with SSD. Results from studies and satisfaction questionnaire confirmed the superiority of $\mathrm{CI}$ and significant performance improvement regarding sound localization, speech perception and marked tinnitus improvement.

\section{References}

1. Baguley DM, Bird J, Humphriss RL, Prevost AT (2006) The evidence base for the application of contralateral bone anchored hearing aids in acquired unilateral sensorineural hearing loss in adults. Clin Otolaryngol 31(01): 6-14.

2. Widen JE, Folsom RC, Cone Wesson B (2000) Identification of neonatal hearing impairment: hearing status at 8 to 12 months corrected age using a visual reinforcement audiometry protocol. Ear Hear 21(05): 471-487.

3. Eiserman WD, Hartel DM, Shisler L, Buhrmann J, White KR, Foust T (2008) Using otoacoustic emissions to screen for hearing loss in early childhood care settings. Int J Pediatr Otorhinolaryngol 72(04): 475-482.

4. Watkin P, Baldwin M (2012) The longitudinal follow up of a universal neonatal hearing screen: the implications for confirming deafness in childhood. Int J Audiol 51(07): 519-528.

5. Lin LM, Bowditch S, Anderson MJ, May B, Cox KM, et al. (2006) Amplification in the rehabilitation of unilateral deafness: speech in noise and directional hearing effects with bone-anchored hearing and contralateral routing of signal amplification. Otol Neurotol 27(02): 172182.

6. Niparko JK, Cox KM, Lustig LR (2003) Comparison of the bone anchored hearing aid implantable hearing device with contralateral routing of offside signal amplification in the rehabilitation of unilateral deafness. Otol Neurotol 24(01): 73-78.

7. Kral A, Sharma A (2012) Developmental neuroplasticity after cochlear implantation. Trends Neurosci 35: 111-122.

8. Gordon K, Henkin Y, Kral A (2015) Asymmetric Hearing During Development: The aural preference syndrome and treatment options. Pediatrics 136(1): 141-153.

9. van Wieringen A, Boudewyns A, Sangen A, (2018) Unilateral congenital hearing loss in children. Challenges and potentials. Hear Res 372: 29-41. 
10. Sharma A, Dorman MF, Kral A (2005) The influence of a sensitive period on central auditory development in children with unilateral and bilateral cochlear implants. Hear Res 203(1,2): 134-143.

11. Sano H, Okamoto M, Ohhashi K, Iwasaki S, Ogawa K (2013) Quality of life reported by patients with idiopathic sudden sensorineural hearing loss. Otol Neurotol 34(1): 36-40.

12. Al Hanbali S, Dawes P, Lloyd S, Munro KJ (2017) Self-Reported ListeningRelated Effort and Fatigue in Hearing-Impaired Adults. Ear Hear 38: e39-e48.

13. Bess FH, Davis H, Camarata S, Hornsby BWY (2020) Listening-Related Fatigue in Children with Unilateral Hearing Loss. Lang Speech Hear Serv Sch 51: 84-97.

14. Lewis D, Schmid K, OLeary S, Spalding J, Heinrichs Graham E, et al. (2016) Effects of noise on speech recognition and listening effort in children with normal hearing and children with mild bilateral or unilateral hearing loss. J Speech Lang Hear Res 59: 1218-1232.

15. Sharma A, Glick H, Campbell J, Torres J, Dorman M, et al. (2016) Cortica plasticity and reorganizations in pediatric single-sided deafness pre- and post-cochlear implantation: a case study. Otol Neurotol 37(2): e26-e34.

16. Tyler RS, Dunn CC, Witt SA, Preece JP (2003) Update on bilateral cochlear implantation. Curr Opin Otolaryngol Head Neck Surg 11(05): 388-393.

17. Arndt S, Aschendorff A, Laszig R, Beck R, S child C, et al. (2011) Comparison of pseudobinaural hearing to real binaural hearing rehabilitation after cochlear implantation in patients with unilateral deafness and tinnitus. Otol Neurotol 32(1): 39-47.

18. Brown KD, Balkany TJ (2007) Benefits of bilateral cochlear implantation: a review. Curr Opin Otolaryngol Head Neck Surg 15(05): 315-318.

19. Keller WD, Bundy RS (1980) Effects of unilateral hearing loss upon educational achievement. Child Care Health Dev 6(02): 93-100.

20. Blauert J (1997) Spatial Hearing. The Psychophysics of Human Sound Localization. The MIT Press: London, UK.

21. Soeta Y, Nakagawa S (2006) Effects of the frequency of interaural time difference in the human brain. Neuro report 17(05): 505-509.

22. Noble W, Gatehouse S (2004) Interaural asymmetry of hearing loss, Speech, Spatial and Qualities of Hearing Scale (SSQ) disabilities, and handicap. Int J Audiol 43: 100-114.

23. Zwicker E (1991) Dependence of binaural loudness summation on interaural level differences, spectral distribution, and temporal distribution. J Acoust Soc Am 89(2) : 756-764.

24. Fletcher H, Munson WA (1933) Loundess, its definition, measurement, and calculation. J Acoust Soc Am 5: 82-108.

25. Moore BCJ, Gibbs A, Onions G, Glasberg BR (2014) Measurement and modeling of binaural loudness summation for hearing-impaired listeners. J Acoust Soc Am 136: 736-747

26. Van Deun L, van Wieringen A, Van den Bogaert T, Scherf F, Offeciers FE, et al. (2009) Sound localization, sound lateralization, and binaural masking level differences in young children with normal hearing. Ear Hear 30(2): 178-190.

27. Cardieux JH, Firszt JB, Reeder RM (2013) Cochlear implantation in nontraditional candidates: preliminary results in adolescents with asymmetric hearing loss. Otol Neurotol 34(3): 408-415.

28. Ruscetta MN, Arjmand EM, Pratt SR (2005) Speech recognition abilities in noise for children with severe-to-profound unilateral hearing impairment. Int J Pediatr Otorhinolaryngol 69(6): 771-779.

29. Noh H, Park YG (2012) How close should a student with unilateral hearing loss stay to a teacher in a noisy classroom? Int J Audiol 51(6): 426-432.
30. Lieu JE, Karzon RK, Ead B, Tye-Murray N (2013) Do audiologic characteristics predict outcomes in children with unilateral hearing loss? Otol Neurotol 34(9): 1703-1710.

31. Busch T, Vanpoucke F, van Wieringen A (2017) Auditory environment across the life span of cochlear implant users: Insights from data logging. J Speech Lang Hear Res 60(5): 1362-1377.

32. Kral A, Kronenberger WG, Pisoni DB, ODonoghue GM (2016) Neurocognitive factors in sensory restoration of early deafness: a connectome model. Lancet Neurol 15(6): 610-621.

33. Kral A (2013) Auditory critical periods: a review from system's perspective. Neuroscience 5 (247): 117-133.

34. Kral A, Tillein J, Heid S, Hartmann R, Klinke R (2005) Postnatal cortical development in congenital auditory deprivation. Cerebr Cortex 15(5): 552-562.

35. Khosla D, Ponton CW, Eggermont JJ, Kwong B, Don M, et al. (2003) Differential ear effects of profound unilateral deafness on the adult human central auditory system. J Assoc Res Otolaryngol 4(2): 235-249.

36. Schmithorst VJ, Holland SK, Ret J, Duggins A, Arjmand E, et al. (2005) Cortical reorganization in children with unilateral sensorineural hearing loss. Neuroreport 16(5): 463-467.

37. Burton H, Firszt JB, Holden T, Agato A, Uchanski RM (2012) Activation lateralization in human core, belt, and parabelt auditory fields with unilateral deafness compared to normal hearing. Brain Res 15(1454): $33 \mathrm{e} 47$.

38. Lieu JE (2015) Management of children with unilateral hearing loss. Otolaryngol Clin 48(6): 1011-1026.

39. Tillein J, Hubka P Kral A (2016) Monaural congenital deafness affects aural dominance and degrades binaural processing. CerebrCortex 26(4): 1762-1777.

40. Peter N, Kleinjung T (2019) Neuromodulation for tinnitus treatment: an overview of invasive and non-invasive techniques. J Zhejiang Univ Sci B 20(2): 116-130

41. Kiese Himmel C (2002) Unilateral sensorineural hearing impairment in childhood: analysis of 31 consecutive cases. Int J Audiol 41 (1): 57-63.

42. Saffran JR, Aslin RN, Newport EL (1996) Statistical learning by 8-monthold infants. Science 274(5294): 1926-1928.

43. Pisoni DB, Kronenberger WG, Chandramouli SH, Conway CM (2016) Learning and memory processes following cochlear implantation: the missing piece of the puzzle. Front Psychol 7: 493.

44. Martínez-Cruz CF, Poblano A, Conde-Reyes MP (2009) Cognitive performance of school children with unilateral sensorineural hearing loss. Arch Med Res 40(5): 374-379.

45. Ead B, Hale S, DeAlwis D, Lieu JE (2013) Pilot study of cognition in children with unilateral hearing loss. Int J Pediatr Otorhinolaryngol 77(11): 1856-1860.

46. Purcell PL, Shinn JR, Davis GE, Sie KC (2016) Children with unilateral hearing loss may have lower intelligence quotient scores: a metaanalysis. Laryngoscope 126(3): 746-754.

47. Lieu JE (2004) Speech-language and educational consequences of unilateral hearing loss in children. Arch Otolaryngol Head Neck Surg 130: 524-530.

48. Krishnan LA, Van Hyfte S (2016) Management of unilateral hearing loss. Int. J. Pediatr. Otorhinolaryngol 88: 63-73.

49. Borton SA, Mauze E, Lieu JE (2010) Quality of life in children with unilateral hearing loss: a pilot study. Am J Audiol 19(1): 61-72.

50. Bosman AJ, Hol MKS, Snik AFM, Mylanus EA, Cremers CW (2003) Bone anchored hearing aids in unilateral inner ear deafness. Acta Otolaryngol 123(02): 258-260. 
51. Kunst SJW, Leijendeckers JM, Mylanus EAM, Hol MK, Snik AF, et al. (2008) Bone-anchored hearing aid system application for unilateral congenital conductive hearing impairment: audiometric results. Otol Neurotol 29(1): 2-7.

52. Schleich P, Nopp P, DHaese P (2004) Head shadow squelch, and summation effects in bilateral users of the MED-EL COMBI 40/40p cochlear implant. Ear Hear 25(03): 197-204.

53. Litovsky RY, Parkinson A, Arcaroli J (2009) Spatial hearing and speech intelligibility in bilateral cochlear implant users. Ear Hear 30(04): 419431.

54. Dowell RC, Hollow R, Winton E (2004) Outcomes for cochlear implant users with significant residual hearing: implications for selection criteria in children. Arch Otolaryngol Head Neck Surg 130(05): 575-581.

55. Gstoettner WK, Helbig S, Maier N, Kiefer J, Radeloff A, Adunka OF (2006) Ipsilateral electric acoustic stimulation of the auditory system: results of long-term hearing preservation. Audiol Neurotol 11(01Suppl 1): 49-56.

56. Gstoettner WK, van de Heyning P, OConnor AF (2008) Electric acoustic stimulation of the auditory system: results of a multicentre investigation. Acta Otolaryngol 128(09): 968-975.

57. Adunka OF, Buss E, Clark MS, Pillsbury HC, Buchman CA (2008) Effect of preoperative residual hearing on speech perception after cochlear implantation. Laryngoscop 118(11): 2044-2049.

58. Koch DB, Soli SD, Downing M, Osberger MJ (2010) Simultaneous bilatera cochlear implantation: prospective study in adults. Cochlear Implants Int 11(02): 84-99.

59. Dunn CC, Tyler RS, Witt SA (2005) Benefit of wearing a hearing aid on the unimplanted ear in adult users of a cochlear implant. J Speech Lang Hear Res 48(03): 668-680.

60. Firszt JB, Reeder RM, Skinner MW (2008) Restoring hearing symmetry with two cochlear implants or one cochlear implant and a contralateral hearing aid. J Rehabil Res Dev 45(05): 749-767.

61. Van de Heyning P, Vermeire K, Diebl M, Nopp P, Anderson I, et al . (2008) Incapacitating unilateral tinnitus in single-sided deafness treated by cochlear implantation. Ann Otol Rhinol Laryngol 117(9): 645-652.

62. Vermeire K, Van de Heyning P (2009) Binaural hearing after cochlear implantation in subjects with unilateral sensorineural deafness and tinnitus. Audiol Neurotol 14(3): 163-71.

63. Zeitler DM, Dorman MF, Natale SJ, Loiselle L, Yost WA, et al. (2015) Sound source localization and speech understanding in complex listening environments by single-sided deaf listeners after cochlear implantation. Otol Neurotol 36(9): 1467-1471.

64. Dorman MF, ZeitleR D, Cook SJ (2015) Interaural level difference cues determine sound source localization by single-sided deaf patients fit with a cochlear implant. Audiol Neurotol 20(03): 183-188.

65. Akeroyd MA (2006) The psychoacoustics of binaural hearing. Int J Audiol 45(1 Suppl 1): S25-S33

66. Firszt JB, Holden LK, Reeder RM, Cowdrey L King S (2012) Cochlear implantation in adults with asymmetric hearing loss. Ear Hear 33(04): 521-533.

67. Sladen DP, Frisch CD, Carlson ML, Driscoll CL, Torres JH (2017) Cochlear implantation for single-sided deafness: A multicenter study. Laryngoscope 127(1): 223-228.

68. Hochmair Desoyer I, Schulz E, Moser L (1997) The HSM sentence test as a tool for evaluating the speech understanding in noise of cochlear implant users. Am J Otol 18(6Suppl): 18-83.

69. Wagener K, Kuhnel, K, Kollmeier B (1999) Development and evaluation of a German sentence test: I. Design of the Oldenburger sentence test. Z Audiol 38: 4Y15.
70. Wagener K, Brand T, Kollmeier B (1999) Development and evaluation of a German sentence test: Part III. Evaluation of the Oldenburg sentence test. Z Audiol 38: 86Y95.

71. Peterson GE, Lehiste I (1962) Revised CNC lists for auditory tests. J Speech Hear Disord 27: 62-70.

72. Nilsson M, Soli SD, Sullivan JA (1994) Development of the hearing in noise test for the measurement of speech reception thresholds in quiet and in noise. J Acoust Soc Am 95: 1085-1099.

73. Lamel FL, Kassel RH, Seneff S (1986) Speech database development: Design and analysis of the acoustic-phonetic corpus. Proceedings of DARPA Speech Recognition Workshop Report No. SAIC-86/1546.

74. Távora Vieira D, Marino R, Acharya A, Rajan GP (2015) The impact of cochlear implantation on speech understanding, subjective hearing performance and tinnitus perception in patients with unilateral severe to profound hearing loss. Otol Neurotol 36(3): 430-436

75. Bench J, Kowal A, Bamford J (1979) The BKB (Bamford-Kowal-Bench) sentence lists for partially-hearing children Br J Audiol 13: 108Y12.

76. Eggermont JJ, Roberts LE (2004) The neuroscience of tinnitus. Trends Neurosci 27: 676-682.

77. Kaltenbach JA, Afman CE (2000) Hyperactivity in the dorsal cochlear nucleus after intense sound exposure and its resemblance to toneevoked activity: A Physiological model for tinnitus. Hear Res 140: 165172.

78. Muhlnickel W, Elbert T, Taub E (1998) Reorganization of auditory cortex in tinnitus. Proc Natl Acad Sci USA 950: 10340-10343.

79. Salvi RJ, Wang J, Ding D (2000) Auditory plasticity and hyperactivity following cochlear damage. Hear Res 147: 261-274.

80. Vanneste S, De Ridder D (2012) The auditory and non-auditory brain areas involved in tinnitus: an emergent property of multiple parallel overlapping subnetworks. Front Syst Neurosci 6:31.

81. Ramakers GG, van Zon A, Stegeman I, (2015) The effect of cochlear implantation on tinnitus in patients with bilateral hearing loss: a systematic review. Laryngoscope 125(11): 2584-2592.

82. Ramos Á, Polo R, Masgoret E, (2012) Cochlear implant in patients with sudden unilateral sensorineural hearing loss and associated tinnitus. Acta Otorrinolaringol Esp 63(1): 15-20.

83. Tokita J, Dunn C, Hansen MR (2014) Cochlear implantation and singlesided deafness. Curr Opin Otolaryngol Head Neck Surg 223: 53-358.

84. Newman CW, Jacobson GP, Spitzer JB (1996) Development of the Tinnitus Handicap Inventory. Arch Otolaryngol Head Neck Surg 122: 143-148.

85. Miller MD, Ferris DG (1993) Measurement of subjective phenomena in primary care research: The visual analogue scale. Fam Pract Res J 13: $15-24$.

86. Mertens G, De Bodt M, Van de Heyning P (2016) Cochlear implantation as a long-term treatment for ipsilateral incapacitating tinnitus in subjects with unilateral hearing loss up to 10 years. Hear Res 33: 11-16.

87. Wewers ME, Lowe NK (1990) A critical review of visual analogue scales in the measurement of clinical phenomena. Res Nurs Health 13(4): 227 236.

88. Punte AK, Vermeire K, Hofkens A (2011) Cochlear implantation as a durable tinnitus treatment in single-sided deafness. Cochlear Implants Int 12: S26-S29.

89. Buechner A, Brendel M, Lesinski Schiedat A (2010) Cochlear implantation in unilateral deaf subjects associated with ipsilateral tinnitus. Otol Neurotol 31: 1381-1385. 
90. Härkönen K, Kivekäs I, Rautiainen M, Kotti V, Sivonen V, et al. (2015) Single-sided deafness: The effect of cochlear implantation on quality of life, quality of hearing, and working performance. ORL J Otorhinolaryngol Relat Spec 77(6): 339-345.

91. Macías AR, Gonzalez JCF, Manrique M (2015) Cochlear implants as a treatment option for unilateral hearing loss, severe tinnitus and hyperacusis. Audiol Neurotol 20: 60-66.

92. Quaranta N, Bartoli R, Quaranta A (2004) Cochlear implants: Indications in groups of patients with borderline indications. A review Acta OtoLaryngologica Supplementum 552: 68-73.

93. Wie OB, Pripp A H, Tvete O (2010) Unilateral deafness in adults: Effects on communication and social interaction. Ann Otol Rhinol Laryngol 119(11): 772-781.

94. Liu YW, Cheng X, Chen B, Peng K, Ishiyama A, et al. (2018) Effect of tinnitus and duration of deafness on sound localization and speech recognition in noise in patients with single sided deafness. Trends in hear 22: 1-14.

95. Mertens G, Kleine PA, De Ridder D, Van de Heyning P (2013) Tinnitus in a single-sided deaf ear reduces speech reception in the non-tinnitus ear. Otol Neurotol 34(4): 662-666.

96. Punte AK, De Ridder D, Van de Heyning P (2013) On the necessity of full length electrical cochlear stimulation to suppress severe tinnitus in single-sided deafness. Hear Res 295: 24-29.

97. Vlastarakos PV, Nazos K, Tavoulari EF, Nikolopoulos TP (2014) Cochlear implantation for single-sided deafness: the outcomes. An evidencebased approach. Eur Arch Otorhinolaryngol 271(8): 2119-2126.

98. van Zon A, Peters JPM, Stegeman I, Smit AL, Grolman W (2015) Cochlear implantation for patients with single-sided deafness or asymmetrical hearing loss: A Systematic review of the evidence. Otol Neurotol 36(2): 209-219.

99. Finke M, Bonitz H, Lyxell B, Illg A (2017) Cochlear implant effectiveness in postlingual single-sided deaf individuals: What's the point? Int J Audiol 56(6): 417-423.

100. Louza J, Hempel JM, Krause E, Berghaus A, Müller J, et al. (2017) Patient benefit from Cochlear implantation in single-sided deafness: A 1-year follow up. Eur Arch Oto-Rhino-Laryngol 274(6): 2405-2409.

101. Hansen MR, Gantz BJ, Dunn C (2013) Outcomes after cochlear implantation for patients with single-sided deafness, including those with recalcitrant Meniere's disease. Otol Neurotol 34(9): 1681-1687.

102. Stelzig Y, Jacob R, Mueller J (2011) Preliminary speech recognition results after cochlear implantation in patients with unilateral hearing loss: a case series. J Med Case Reports 5(5): 343.

103. Arndt S, Laszig R, Aschendorff A, Hassepass F, Beck R, et al. (2017) Cochlear implant treatment of patients with single-sided deafness or asymmetric hearing loss. German version. HNO 65(7): 586-598.

104. Baguley D, McFerran D, Hall D (2013) Tinnitus. Lancet 382(9904): 1600-1607.
105. Friedmann DR, Ahmed OH, McMenomey SO, Shapiro WH, Waltzman SB et al. (2016) Single-sided Deafness Cochlear Implantation: Candidacy, Evaluation, and Outcomes in Children and Adults. Otol Neurotol 37(2): e154-160.

106. Hol MK, Kunst SJ, Snik AF, Bosman AJ, Mylanus EA, et al. (2010) Bone-anchored hearing aids in patients with acquired and congenital unilateral inner ear deafness (Baha CROS): clinical evaluation of 56 cases. Ann Otol Rhinol Laryngol 119(7): 447-454.

107. Kiefer J, Pok M, Adunka O (2005) Combined electric and acoustic stimulation of the auditory system: results of a clinical study. Audiol Neurotol 10(03): 134-144.

108. Kitoh R, Moteki H, Nishio S, Shinden S, Kanzaki S, et al. (2016) The effects of cochlear implantation in Japanese single-sided deafness patients: five case reports. Acta Otolaryngol 136(5): 460-464.

109. Kompis M, Wimmer W, Caversaccio M (2017) Long term benefit of bone anchored hearing systems in single sided deafness. Acta Otolaryngol 137(4): 398-402.

110. Kral A, ODonoghue GM (2010) Profound deafness in childhood. N Engl J Med 363 (15): 1438-1450.

111. Mertens G, De Bodt M, Van de Heyning P (2017) Evaluation of LongTerm Cochlear Implant Use in Subjects with Acquired Unilateral Profound Hearing Loss: Focus on Binaural Auditory Outcomes. Ear Hear 38(1): 117-25.

112. Newman CW, Sandridge SA, Wodzisz LM (2008) Longitudinal benefit from and satisfaction with the Baha system for patients with acquired unilateral sensorineural hearing loss. Otol Neurotol 29(8): 1123-1131.

113. Nicole P, Nuwan L, Flurin P, Alexander H, Tobias K (2019) The influence of cochlear implantation on tinnitus in patients with single-sided deafness: A systematic review Otolaryngol Head Neck Surg 161(4): 576-588.

114. Seo YJ, Kim HJ, Moon IS, (2015) Changes in tinnitus after middle ear implant surgery: comparisons with the cochlear implant. Ear Hear 36(6): 705-709.

115. Stevens SS (1957) On the psychophysical law. Psychol Rev 64: 153181.

116. Van de Heyning P, Távora-Vieira D, Mertens G, Van Rompaey V, Rajan GP, et al. (2016) Towards a unified testing framework for single-sided deafness studies: A Consensus Paper. Audiol Neurotol 21(6): 391-398.

117. Van Deun L, van Wieringen A, Scherf F, Deggouj N, Desloovere C, et al. (2010) Earlier intervention leads to better sound localization in children with bilateral cochlear implants. Audiol Neuro Otol 15(1): 7-17.

118. Wimmer W, Kompis M, Stieger C, Caversaccio M, Weder S (2017) Directional Microphone Contralateral Routing of Signals in Cochlear Implant Users: A Within-Subjects Comparison. Ear Hear 38(3): 368373. 
(c) (9) This work is licensed under Creative

To Submit Your Article Click Here: Submit Article

DOI: 10.32474/SJ0.2020.05.000209

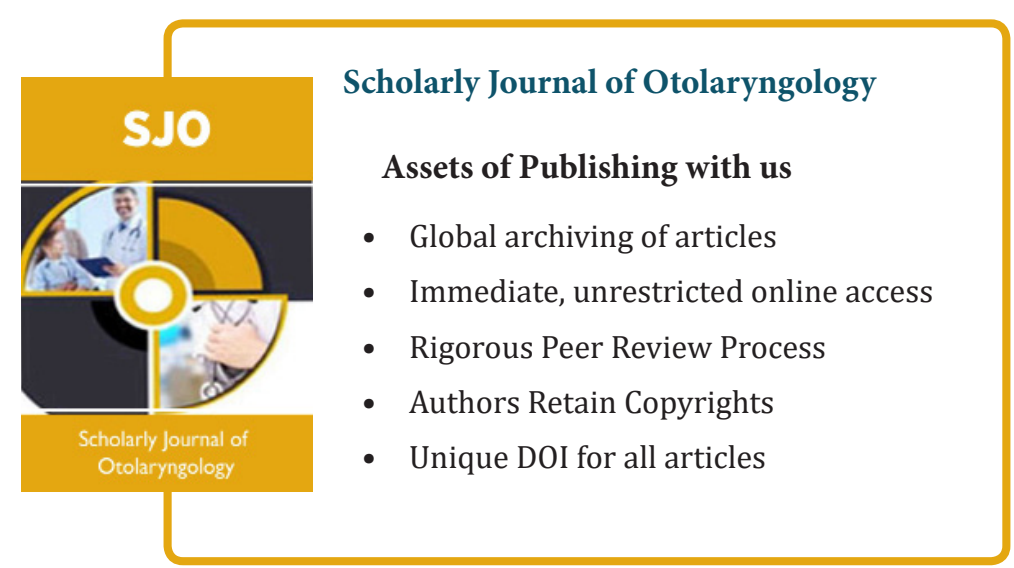

